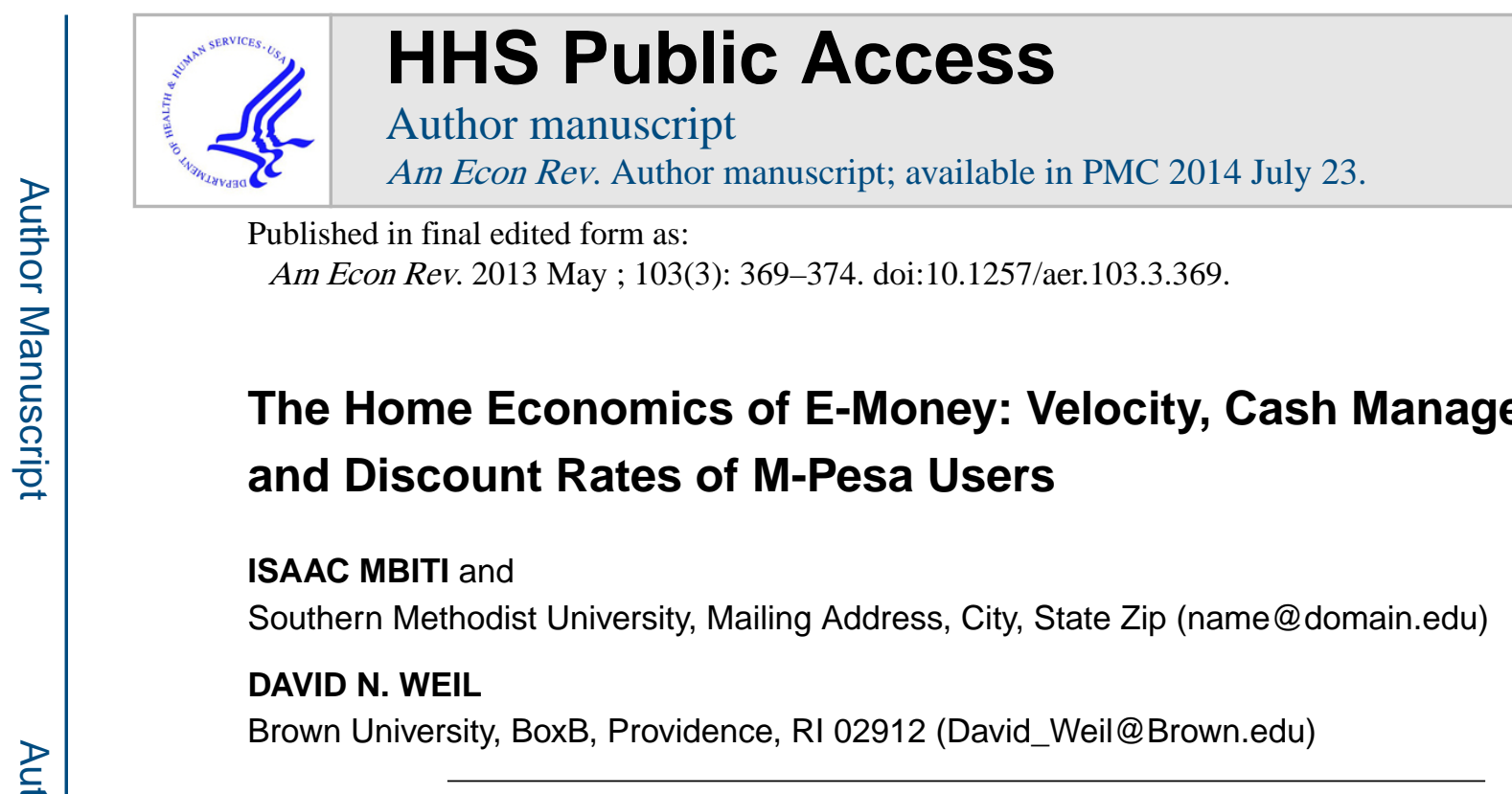

M-Pesa, a service operated by the mobile phone network Safaricom in Kenya, allows users to deposit money onto their telephone handsets, transfer e-money to another user with a simple text message, and withdraw cash at one of thousands of outlets throughout the country. The system is safer, cheaper, and far faster than the money transfer systems that it replaced. Although only five years old, M-Pesa has achieved remarkable penetration into the Kenyan economy. As of September, 2011, there were 32,000 M-Pesa outlets at which individuals could exchange cash for e-float or vice-versa, in a country that as of 2009 had 491 bank branches, 500 postbank branches, and 352 ATMs (Mas and Ng'weno, 2009). In the six month period April-September, 2011, the volume of transfers was Ksh. 314 billion, compared to nominal GDP of Ksh. 2.99 trillion that year. (For the period from which our data are drawn, the market exchange rate was approximately $75 \mathrm{Ksh} /$ dollar and the PPP exchange rate was approximately $35 \mathrm{Ksh} . /$ dollar).

At present, M-Pesa is primarily a money transfer system. However, it has the potential to evolve in two exciting directions: first as a gateway via which unbanked households can access financial services, and second, as a transaction medium, with e-money partially replacing cash. ${ }^{1}$ Even in its current form, however, M-Pesa represents a dramatic change in the economic environment of Kenyan households. Further, data on how households use MPesa allows for insight into the objectives of and constraints on their money management choices, and consumption more generally.

\title{
I. Background
}

Table 1 shows a simplified version of the fee schedule (we ignore transfers to and withdrawals by non-registered users, as these are relatively rare). A notable characteristic of the schedule is the "price notches," in the sense of Slemrod (2010): points at which an incremental change in customer behavior causes a discrete jump in costs. The incentives at price notches are far stronger than those associated with kinks in price schedules such as changes in marginal tax rates. For example, the fee for withdrawing up to $2,500 \mathrm{Ksh}$ is 25

\footnotetext{
${ }^{1}$ As discussed in Mbiti and Weil (2011), Safaricom introduced a savings product, M-Kesho, as well as an insurance product, both of which are linked to the M-Pesa account. Safaricom recently (in December, 2012) announced the launch of a new service M-Shwari that is essentially an improved version of M-Kesho offering customers a way to earn interest on balances and also obtain small loans through its partner commercial bank.
} 
Ksh., while the fee for withdrawing 2,501-5,000 Ksh. is $45 \mathrm{Ksh}$. Thus, a person who withdraws 2,600 Ksh. will be paying a marginal fee of $20 \mathrm{Ksh}$. (20\%) on the last $100 \mathrm{Ksh}$. withdrawn compared to a fee of $1 \%$ on the first $2,500 \mathrm{Ksh}$. Withdrawn. Below we examine the behavioral response to these kinks.

\section{Monetary Characteristics of E-Money}

\section{A. Velocity}

For the purposes of understanding where M-Pesa fits into a broader monetary framework, we are interested in calculating the "velocity" of M-Pesa. In standard monetary economics, there are two different definitions of velocity that are used. "Income velocity" is nominal GDP divided by the relevant money stock. "Transactions velocity" is defined as the frequency with which the average unit of money is used in transactions. Although in some ways more fundamental than income velocity, transactions velocity is much harder to measure, because doing so requires being able to observe actual transactions.

In the case of M-Pesa, the potentially relevant transactions are the creation of a unit of emoney (corresponding to a deposit of cash with an M-Pesa agent), transfer of e-money from one user to another, and withdrawal of cash (extinguishing of a unit of M-Pesa). Further, among transfers that take place, some will be in the nature of payments (for example, a user transfers e-cash from her account to that of a merchant in return for goods and services), while others will be in the form of a gift (for example, a one family member sending money to another). Anecdotally, we believe that the majority of transfers observed are of the latter type, although this may change as the system matures.

As our measure of M-Pesa velocity, we focus only on transfers. Our measure of M-Pesa velocity is thus the total value of person- to-person transfers (i.e. transfers in which neither party is an M-Pesa agent) per unit time divided by the average outstanding balance of e-float We call this "transfer velocity." For example, if 100 units of e-float are created at the beginning of month, transferred from person to person five times in the month, and extinguished at the end the month, then monthly transfer velocity will be five. Notice that having 100 units of e-float transferred from person to person five times in the month could happen either because the people receiving transfers then transferred the e-float to someone else or because each time a transfer was received, the recipient withdrew his cash and a new user deposited cash and received e-float.

Of the two numbers required to measure velocity, the harder one to obtain is the outstanding balance of e-float. All money deposited to create e-float is held by a trust fund which holds deposits in commercial banks. Thus, the outstanding balance of e-float is in principle perfectly observable at any point in time, although the information is not normally made public. Weil, Mbiti, and Mwega (2012) use monthly data on the size of the trust balance monthly from July, 2007 through December, 2011.

While the trust balance is by construction identical to the quantity of e-float outstanding, to calculate transfer velocity, we want to adjust for e-cash that is held by M-Pesa agents. We construct an estimate of this quantity by subtracting estimated e-cash held on the phones of 
M-Pesa agents from the trust balance. Eijkman, Kendall, and Mas (2010) report end of day e-float for different types of M-Pesa outlets. These range from 90,000 Ksh. for rural stores to $40,000 \mathrm{Ksh}$. for city stores. Rural stores have particularly high end of day float because they do a primarily cash-out business. City stores did a more balanced business, though with an excess of cash-in over cash-out. In our calculations we chose a value of 50,000 Ksh. per MPesa agent. Multiplying this by the number of M-Pesa agents gives our estimate of total ecash held by M-Pesa agents. From the Safaricom web site, we have data on the number of agents monthly from April 2007 through April of 2011. For most of the existence of MPesa, the ratio of e-float held on agent phones to total e-float has fluctuated narrowly within the range of $10-12 \%$

The other piece of information required for the calculation of transfer velocity is the monthly value of person to person transfers. This is reported by Safaricom for the period April 2007April 2010. Using this data, Figure 1 shows our calculated value of monthly transfer velocity. The series shows a significant upward trend, rising from roughly two transfers per month in the first year of M-Pesa's operation to roughly four in the last few months for which we have data.

The calculated values of velocity seem to indicate that M-Pesa is functioning as a hybrid of a money transfer system, on the one hand, and a means for storing value, on the other. Velocity of four, for example, implies that the average unit of e-cash was transferred once per week. If M-Pesa were purely being used as a money transfer system, we might expect that velocity would be significantly higher. For example, a simple deposit-transfer-withdraw transaction might involve e-cash being created (in the sense that it is transferred from an agent to a customer), transferred, and extinguished (transferred back to an agent's phone) in much less than a day. This would imply a velocity of over 30 transfers per month. Since we know anecdotally that at least some users indeed do not keep e-cash on their phones for very long, our estimates of velocity imply that some other users are keeping their cash on phones for significantly longer than one week. Such a situation would imply that most e-cash at any point in time is held by non-frequent transactors, even though most transfers are done by frequent transactors.

Velocity can be written as the ratio of monthly transfers per customer to average balances held per customer. Weil, Mbiti, and Mwega (2012) find that rising monthly transfers per customer were the major factor leading velocity to rise, although this series was quite stable around 2,700 Ksh. after December, 2008. Balances of e-cash per customer are stable, in the neighborhood of Ksh. 800, although they fall by about $20 \%$ from July of 2009 to April of 2011.

One of the reasons that economists care about velocity is that it measures the degree to which different components of the money supply contribute to aggregate demand. Were it the case that e-money had a notably higher velocity than other types of money, then it would be possible that conventionally measured monetary aggregates were understating the effective money supply. For the present, however, this is not a concern, because M-Pesa is still very small. In December 2011, currency outside of banks (M0) was 137 billion shillings, while currency plus demand deposits (M1) was 623 billion shillings (Central Bank 
of Kenya, 2011). By contrast, in that month, the balance of e-float outstanding was only Ksh. 17.4 billion.

\section{B. The E-Money Loop}

Irving Fisher defined the "cash loop" as the number of transactions that a unit of currency goes through between being withdrawn from a bank and returning to a bank. Analogously, we can think of the "e-money loop" as the number of transfer transactions that the average unit of M-Pesa goes through between being transferred onto a customer phone and being transferred back from a customer phone to the phone of an M-Pesa agent.

As with velocity, we can put together available scraps of information to get an estimate of the length of the e-money loop, Kamenyi and Ndung'u (2009) give the value of "deposits plus withdrawals" for the period July 2007-July 2009. We combine this with data from Safaricom on the monthly value of person-to-person transfers. For a system that is not growing over time, the relationship between deposits, withdrawals, transfers, and the length of the e-money loop is ${ }^{2}$

$$
\text { looplength }=\frac{2 \times \text { transfers }}{\text { deposits }+ \text { withdrawals }}
$$

Figure 2 shows our calculated loop length. It is interesting to note that in the data the emoney loop starts out at slightly less than one before trending up to almost exactly one. A loop length of one would obtain if all transactions took the form of deposit-transferwithdraw, while a length greater than one would be observed if some people who received a transfer sent e-money on somewhere else without doing a withdrawal. Similarly, loop length will be reduced to the extent that people use their phones to store money without it ever being transferred. Of course, it is possible that there was a good deal of both these activities (receiving money and transferring it onward without taking money out, on the one hand, and depositing and withdrawing without transferring, on the other), but the data are suggestive, at least to us, of the overwhelming majority of use being of the deposit-transfer-withdraw type.

Observation of the length of the e-money loop provides a convenient diagnostic about the extent to which e-money is substituting for cash (which has a long loop length) as means of transactions. Clearly, in this data, little or no such substitution is taking place.

\footnotetext{
${ }^{2}$ The key assumption required to derive this equation is that the system is in a steady state, where monthly deposits are equal to monthly withdrawals. In this case (deposits + withdrawals)/2 is just equal to the quantity of deposits. Also, in this case, transfers made in a given month would be equal to transfers that would eventually be made with the e-money created in a given month (which in turn would be equal to that month's deposits.) The formula is not fully accurate, sinceM-Pesa was in fact growing over time. Given information on the rate of growth M-Pesa and M-Pesa velocity, one could construct a better estimate, but our sense is that it would not differ significantly.
} 


\section{Household Cash Management}

\section{A. Transaction Frequency and Size}

Weil, Mbiti and Mwega (2012) examine data on the frequency of M-Pesa use from the 2009 FinAccess Survey. Focusing their regression analysis on M-Pesa users, they show that urban users, highly educated users (secondary school graduates and above), and individuals with more assets used M-Pesa more frequently than their rural, less education and poorer counterparts. Their estimates show that, for instance, an urban M-Pesa user conducts six more transaction per annum relative to a non-urban user, while asset poor M-Pesa users conduct 5 fewer transactions per year relative to "non-asset poor" users.

The FinAccess Survey also contains information on frequency of M-Pesa use among indivividuals who describe themselves as users. For example, among men, 1.2\% report using M-Pesa daily $12.5 \%$ weekly, $32.4 \%$ monthly, and $53.9 \%$ irregularly. Mbiti and Weil calculate annual frequencies of use from these data. Some of their calculated values are men 21.4; women 15.7; banked individuals 27.8; non-banked 10.4; rural 13.5; urban 23.9.

One implication from this data is that while many individuals do not use M-Pesa frequently, the average transaction (deposit, withdrawal, or transfer) is made by a frequent user. Mbiti and Weil calculate that daily users account for $32 \%$ of transactions, weekly users for $41 \%$ of transactions, monthly users $21 \% \mathrm{t}$, and irregular users account for only $6 \%$.

Complementing this survey data, Mbiti and Weil also obtained data on withdrawals and deposits from three M-Pesa agents: Cyber Center, an urban outlet near one of the markets in the city of Kisumu; Katito, a small town with a population of roughly five thousand, located in a rural area; and Homa Bay, a provincial market town with a population of roughly 20,000 on a main highway (more information is given by Eijkman, Kendall and Mas, 2010). Table 2 gives data on the distribution of withdrawals. The most striking finding in this data is the extent to which a large part of the distribution is composed of very small withdrawals.

Mbiti and Weil also present histograms showing the distribution of withdrawal amounts. They find that there is no concentration of withdrawals at amounts corresponding to price notches, other than the lumping one would expect at round-number amounts. For example, at all three outlets, withdrawals of 2,500 K.Sh. (just below a price notch) are much less common than withdrawals of either 2,000 or 3,000 K.Sh.

\section{B. Implied Discount Rates}

Our knowledge of how individuals manage their M-Pesa accounts is imperfect and circumstantial. Far better data are locked away in Safaricom's computers. Nonetheless, we can pull together several pieces of information to paint a suggestive picture. Specifically, we note that (1) Most M-Pesa transactions are made by frequent users; (2) there is little evidence of spikes in the density of withdrawals at points where there is a price notch; (3) the average time that a unit of M Pesa remains on a user phone is about one week. These observations suggest that the majority of users do not use their phones for storing value, and that the majority of transactions in the system involve one user depositing money to a phone and transferring it while a second user withdraws cash soon after receiving a transfer. ${ }^{3}$ 
These observations of behavior allow for insight into households' operative discount rates. Although M-Pesa balances do not pay explicit interest, holding money in M-Pesa does yield interest in the form of reducing transaction costs.

Consider a very simple model of a household that receives small, regular monthly transfers. One strategy would be to withdraw each transfer as it is received. An alternative would be to group two or more transfers together and withdraw them all at once (for simplicity in this example, the only alternative strategy we consider is grouping two transfers at a time together). The latter strategy holds money on the M-Pesa account for longer, but involves lower costs.

Let $W$ be the monthly transfer received, and $C$ be the withdrawal cost (we assume that $W$ is such that $2 W$ can be withdrawn at the same cost as $W$ ). The monthly interest rate $r$ at which an individual would be indifferent between these two strategies is given implicitly by the equation

$$
W-C+\frac{W-C}{1+r}=\frac{2 W-C}{1+r}
$$

Using values of $W=1,000$ and $C=25$, which would be consistent with the M-Pesa fee schedule and the data we have on the distribution of withdrawals, implies that a household that makes monthly withdrawals is discounting future cash flows at a rate of at least $2.6 \%$ per month (36\% per year). Extending this analysis to incorporate the behavior of senders, who could also save money by transferring more money less frequently, would further raise the implied discount rate.

From this data is seems reasonable to conclude that a significant fraction of withdrawals are made by people who are applying high time discount rates, since otherwise they would be grouping their withdrawals into more economical chunks.

It is important to note that the high financial discount rates that households apply to cash that moves through M-Pesa do not necessarily imply that households highly discount the future consumption flows or utility. As in a standard Baumol-Tobin model of cash management, another reason to hold small cash balances is if there is a high cost of holding cash itself. Such a cost could be due to theft in a conventional sense, which can be viewed as a tax on cash balances. However, crime rates would have to be extremely high to justify the behavior we see. A more likely cost of holding cash is the high implicit tax represented by the ability of other family members to request either gifts or loans from one's available cash balances. This is notion is supported by Ashraf (2009) who reports that women in Kenya often form secret saving societies to hide income from their husbands. Finally, and somewhat similarly, holdings of cash may simply raise temptations to spend that individuals find impossible to resist. The inability to save cash-holdings has been shown to be a constraint to fertilizer adoption in Western Kenya (Duflo et al. 2010) and promotes participation in ROSCAS

\footnotetext{
${ }^{3}$ Our view that individuals do not use their phones for storing value runs counter to the result reported in Jack and Suri (2011) that three out of four M-Pesa users report using it to save money.
} 
which can act as a commitment saving device (Gugerty, 2007). It could be that the extra transaction costs associated with holding small cash balances are a price worth paying to avoid giving in to these temptations. Of course, such an explanation would only be correct if balances held in M-Pesa were less subject to spending pressure than those held in cash .

\section{REFERENCES}

Eijkman, Frederik, Kendall, Jake, Mas, Ignacio. Bridges to Cash: the retail end of M-PESA. 2010. mimeo

Central Bank of Kenya. Statistical Bulletin. Dec.2011

Jack, William, Suri, Tavneet. Mobile Money: The Economics of M-Pesa. 2011. NBER Working Paper 16721

Kimenyi, Mwangi, S., Ndung'u, Njuguna S. Expanding the Financial Services Frontier: Lessons From Mobile Phone Banking in Kenya. Brookings Institution; Oct 16. 2009

Mbiti, Isaac, Weil, David N. Mobile Banking: The Impact of M-Pesa in Kenya. Jun. 2011 NBER Working paper 17129

Slemrod, Joel. Buenas Notches: Lines and Notches in Tax System Design. University of Michigan; 2010. mimeo

Weil, David, N., Mbiti, Isaac, Mwega, Francis. The Implications of Innovations in the Financial Sector on the Conduct of Monetary Policy in East Africa. 2011. Report submitted to the International Growth Centre Tanzania Country Programme 


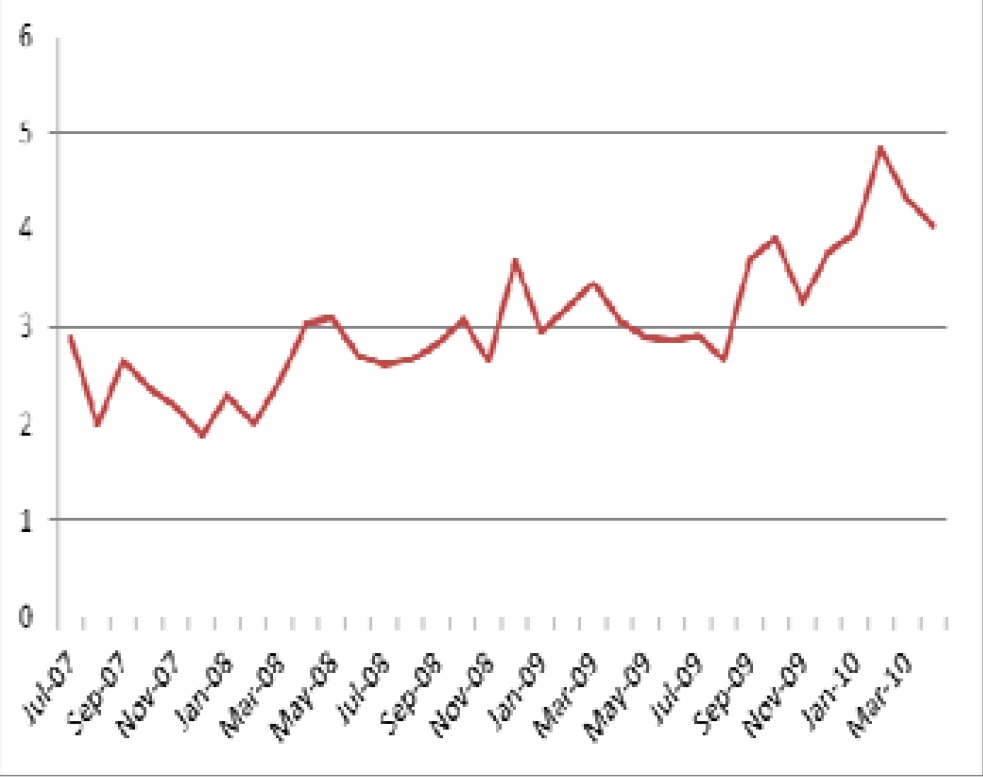

FIGURE 1.

Transfer Velocity of M-Pesa 


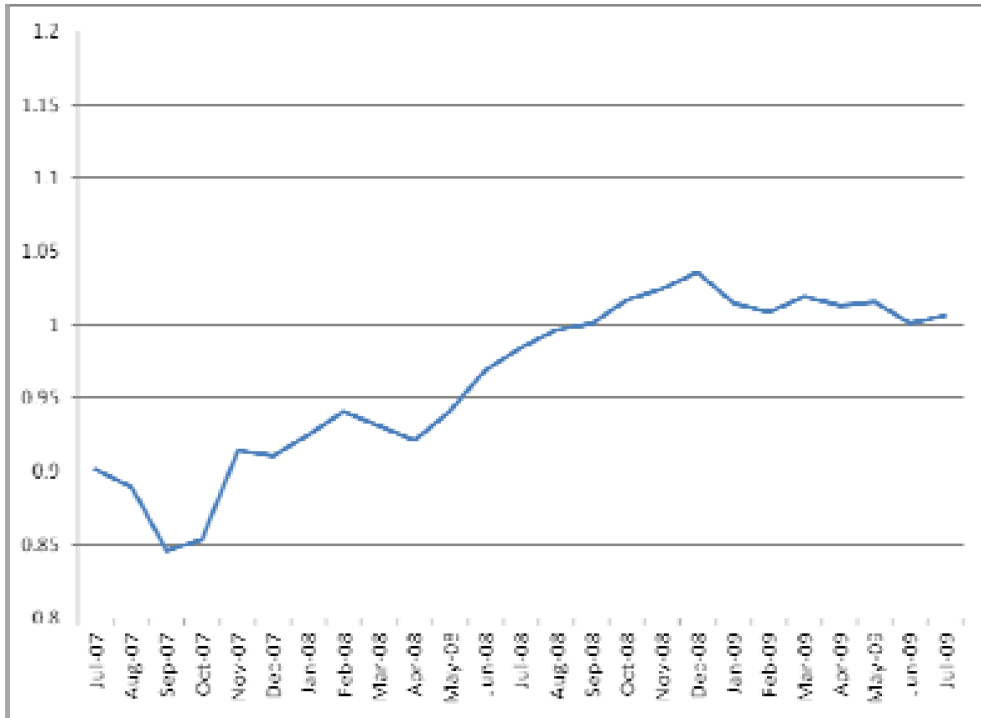

FIGURE 2.

Length of the E-Money Loop 


\section{TABLE 1}

M-Pesa Fee Schecule (K.Sh)

\begin{tabular}{lcc}
\hline Transaction Type & Range & Charge \\
\hline Deposit Cash & $100-35,000$ & Free \\
Send Money to Registered User & $100-35,000$ & 30 \\
Withdraw Cash (Registered User) & $100-2,500$ & 25 \\
& $2,501-5,000$ & 45 \\
& $5,001-10,000$ & 75 \\
& $10,001-20,000$ & 145 \\
& $20,001-35,000$ & 170 \\
\hline
\end{tabular}


MBITI and WEIL

Page 11

TABLE 2

Distribution of Withdrawal Amounts (K.Sh)

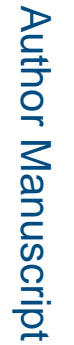

\begin{tabular}{lccc}
\hline & Cyber Center & Katito & Homa Bay \\
\hline Observations & 3,477 & 6,401 & 2,787 \\
Mean & 2,757 & 1,402 & 5,762 \\
$10^{\text {th }}$ percentile & 300 & 250 & 390 \\
$25^{\text {th }}$ percentile & 500 & 475 & 700 \\
Median & 1,000 & 900 & 1,970 \\
$75^{\text {th }}$ percentile & 2,850 & 1,680 & 6,500 \\
$90^{\text {th }}$ percentile & 6,370 & 3,000 & 18,500 \\
\hline
\end{tabular}

를

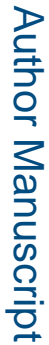

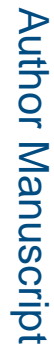

Am Econ Rev. Author manuscript; available in PMC 2014 July 23. 